\title{
PENERAPAN MEDIA POP UP BOOK UNTUK MENINGKATKAN KETERAMPILAN PROSES IPA PADA MAHASISWA PGSD
}

\author{
OLEH : \\ INDAH PRATIWI ${ }^{1}$, CHAIRUNNISA AMELIA ${ }^{2}$ \\ (UNIVERSITAS MUHAMMADIYAH SUMATERA UTARA ${ }^{1,2}$ )
}

\begin{abstract}
This study aims to determine the improvement of science process skills possessed students by using the PopUp Book learning media. The method used in data collection is documentation, observation and tests. In this study, researchers or lecturers use pop-up media that aiming to see an enchance in the science learning process skills of PGSD students. This study can be seen from the average assessment classically to see the science process skills possessed by students in each indicator of the science process skills.

In $1^{\text {st }}$ indicator, the skills to observe before using the media are $49.1 \%$ and after using the media are $82.9 \%$. In the $2^{\text {nd }}$ Indicator, the skills of formulating a hypothesis before using the media are $42.4 \%$ and after using the media are 79.5.\%. In the $3^{\text {rd }}$ Indicator, the skills of planning an experiment before using the media are $46.2 \%$ and after using the media are $85.7 \%$. In $4^{\text {th }}$ indicator, the skills of conducting experiments before using the media are $54.3 \%$ and after using the media are $90.5 \%$. In the $5^{\text {th }}$ Indicator, the skills to predict before using the media are $43.3 \%$ and after using media are $80.9 \%$. In the $6^{\text {th }}$ indicator, the skills of applying concepts before using media are $41.9 \%$ and after using media are $78.6 \%$. In the $7^{\text {th }}$ indicator, communication skills before using media are $41.9 \%$ and after using media are $90 \%$. The result shows that the Pop Up Book learning media can improve the science process skills of PGSD students.
\end{abstract}

Keywords :Improvement of science process skills possessed students by using the Pop Up Book learning media.

\section{PENDAHULUAN}

\section{Latar Belakang}

Kurikulum di setiap lembaga pendidikan, khususnya perguruan tinggi, Pendidikan IPA merupakan salah mata kuliah umum yang terdapat pada program studi Pendidikan Guru Sekolah Dasar (PGSD). Hal ini bertujuan agar lulusan perguruan tinggi selain memiliki kompetensi lulusan di bidangnya, juga memiliki 
kreatifitas dalam menciptakan proses pembelajaran yang menarik dan menyenangkan. Mahasiswa FKIP UMSU perlu dibekali kemampuan dalam membuat media pembelajaran IPA pada mata kuliah Konsep Dasar, agar pembelajaran tersebut bermakna dalam proses pembelajaran. Tujuan dalam menyusun media pembelajaran Pendidikan IPA ini agar mahasiswa mampu meningkatkan kreatifitasnya dalam membuat pembelajaran lebih menarik dan dapat dengan mudah dipahami.

Sarana penunjang dalam perkuliahan Mata Kuliah Pendidikan IPA mutlak diperlukan dalam membantu dalam capaian hasil pembelajaran yang efektif. Sarana tersebut antara lain adalah media pembelajaran IPA. Hasil observasi awal bahwa media pembelajaran IPA sangat diperlukan dalam proses pembelajaran yang dapat digunakan dalam meningkatkan kreatifitas mahasiswa. Penggunaan media pembelajaran IPA dalam proses pembelajaran di kelompok sangat membantu kelompok untuk belajar kritis dan lebih menekankan ke dalam peningkatan kreatifitas mahasiswa terhadap media pembelajaran yang diberikan, yang nantinya mahasiswa juga mampu membuat media tersebut.

Untuk keberhasilan suatu pembelajaran yang menggunakan kelompok seperti media pembelajaran IPA diperlukan kreatifitas yang dimiliki diantara peserta didik. Kreativitas merupakan potensi yang dimiliki setiap manusia dan bukan yang diterima dari luar diri individu. Kreativitas yang dimiliki manusia, lahir bersama lahirnya manusia tersebut. Sejak lahir individu sudah memperlihatkan kecenderungan mengaktualisasikan dirinya. Dalam kehidupan ini kreativitas sangat penting, karena kreativitas merupakan suatu kemampuan yang sangat berarti dalam proses kehidupan manusia. Harus diakui bahwa memang sulit 
untuk menentukan satu definisi yang operasional dari kreativitas, karena kreativitas merupakan konsep yang majemuk dan multidimensional sehingga banyak para ahli mengemukakan tentang definisi dari kreativitas.

Kreativitas sebagai proses berpikir yang membawa seseorang berusaha menemukan metode dan cara baru di dalam memecahkan suatu masalah. Kemudian ia menemukan bahwa kreativitas yang penting bukan apa yang dihasilkan dari proses tersebut tetapi yang pokok adalah kesenangan dan keasyikan yang terlihat dalam melakukan aktivitas kreatif. Berdasarkan uraian sebelumnya dapat disimpulkan bahwa kreativitas merupakan suatu proses berpikir yang lancar, lentur dan orisinal dalam menciptakan suatu gagasan yang bersifat unik, berbeda, orisinal, baru, indah, efisien, dan bermakna, serta membawa seseorang berusaha menemukan metode dan cara baru di dalam memecahkan suatu masalah.

Beberapa uraian di atas dapat dikemukakan bahwa kreativitas pada intinya merupakan kemampuan seseorang untuk melahirkan sesuatu yang baru, baik berupa gagasan maupun karya nyata, baik dalam bentuk karya baru maupun kombinasi dari hal-hal yang sudah ada, yang semuanya itu relative berbeda dengan apa yang telah ada sebelumnya.

\section{RumusanMasalah}

Rumusan masalah dalam penelitian ini adalah “ Bagaimana media pembelajaran Pop Up Book mata kuliah Pendidikan IPA pada mahasiswa semester 2 E PGSD dapat meningkatkan keterampilan proses IPA?” 


\section{TujuanPenelitian}

Adapun tujuan penelitian ini adalah untuk meningkatkan keterampilan proses IPA dengan menggunakan media pembelajaran Pop Up Book mata kuliah Pendidikan IPA pada mahasiswa semester 2 E PGSD.

\section{METODE PENELITIAN}

Penelitian ini dilakukan di Universitas Muhammadiyah Sumatera Utara yang berada di jalan Kapten Muchtar Basri No.3 Medan. Penelitian ini dilakukan dengan menggunakan metode Penelitian Tindakan Kelas, untuk melihat peningkatan pembelajaran pada mahasiswa.

Prosedur penelitian yang digunakan adalah yaitu mengetahui permasalahan yang terjadi pada mahasiswa di kelas dengan melakukan tes awal, berikutnya adalah tahapan perencanaan, tahapan pelaksanaan tindakan, melaksanakan observasi dan adanya refleksi.

Teknik pengumpulan data yang digunakan dalam penelitian ini adalah dengan dokumentasi untuk memperoleh informasi yang berkaitan dengan media Pop Up Book pada pembelajaran IPA. Setelah itu melakukan observasi (pengamatan) untuk memperoleh informasi yang berkaitan dengan kualitas pelaksaan KBM. Dan tahapan yang terakhir adalah melakukan tes dengan pengumpulan Pop Up Book untuk memperoleh informasi tentang sejauhmana peningkatan keterampilan proses IPA mahasiswa terhadap materi yang terdapat dalam matakuliah IPA dengan penggunaan media pembelajaran.

Teknik analisa data dengan melakukan reduksi data yang merupakan proses menyeleksi, menentukan fokus, menyederhanakan, meringkas dan 
mengubah bentuk data mentah yang ada dalam catatan lapangan. Setelah direduksi data siap dipaparkan, artinya tahap analisis sampai pada pemaparan data. Data yang diperoleh dari tes awal dan tes akhir diolah untuk mengetahui skor yang diperoleh siswa, sehingga diketahui Persentase Perolehan Hasil (PPH) per mahasiswa. Untuk Persentase Perolehan Hasil (PPH) dari tes kemampuan memecahkan masalah mahasiswa digunakan rumus sebagai berikut:

$$
\mathrm{PPH}=\frac{\text { skor yang diperoleh siswa }}{\text { skor maksimum }} \times 100 \% \quad \text { (Sutomo, 1985) }
$$

Kriteria:

$0 \% \leq \mathrm{PPH}<65 \% \quad$ siswa belum tuntas belajar

$65 \% \leq \mathrm{PPH} \leq 100 \%$ siswa sudah tuntas belajar

Tingkat kemampuan mahasiswa menyelesaikan tes ditentukan dengan kriteria penentuan tingkat penguasaan siswa terhadap materi yang diajarkan sesuai dengan kriteria sebagai berikut: Konversi yang digunakan dalam mengubah skor mentah menjadi skor standar dengan norma absolut adalah didasarkan atas tingkat penguasaan terhadap bahan yang diberikan. Tingkat penguasaan itu akan tercermin pada tinggi rendahnya skor mentah yang dicapai. Adapun pedoman yang digunakan dalam menentukan tingkat penguasaan siswa adalah sebagai berikut:

\section{Skala Lima Norma Absolut}

\begin{tabular}{|c|c|}
\hline Tingkat penguasaan & Kategori \\
\hline $90 \%-100 \%$ & Sangat tinggi \\
\hline $80 \%-89 \%$ & Tinggi \\
\hline $65 \%-79 \%$ & Sedang \\
\hline $55 \%-64 \%$ & Rendah \\
\hline $0 \%-54 \%$ & Sangat rendah \\
\hline
\end{tabular}


Kemudian penentuan ketuntasan belajar mahasiswa secara klasikal dapat ditentukan dengan menggunakan rumus:

$$
\mathrm{PKK}=\frac{\text { banyak siswa yang } \mathrm{PPH} \geq 65 \%}{\text { banyak subjek penelitian }} \times 100 \%
$$

Keterangan :

PKK : Persentase Ketuntasan Klasikal

Berdasarkan kriteria ketuntasan belajar, apabila di kelas tersebut telah mencapai $85 \%$ mahasiswa dengan $\mathrm{PPH} \geq 65 \%$, maka ketuntasan belajar secara klasikal telah tercapai.

\section{HASIL PENELITIAN}

Hasil penelitian penggunaan media pembelajaran IPA untuk meningkatkan keteampilan proses IPA oleh Mahasiswa PGSD sudah dilaksanakan dalam rangka pengumpulan dan pengolahan data. Hal tersebut dapat dilihat pada nilai pada setiap indikatornya.

\begin{tabular}{|c|l|c|c|c|}
\hline No. & \multicolumn{1}{|c|}{ Indikator } & $\begin{array}{c}\text { Sebelum } \\
\text { Menggunakan } \\
\text { Media }\end{array}$ & $\begin{array}{c}\text { Sesudah } \\
\text { Menggunakan } \\
\text { Media }\end{array}$ & $\begin{array}{c}\text { Peningkatan } \\
\text { Penilaian } \\
\text { Secara } \\
\text { Klasikal }\end{array}$ \\
\hline 1. & $\begin{array}{l}\text { Keterampilan } \\
\text { Mengamati }\end{array}$ & $82,9 \%$ & $33,8 \%$ \\
\hline 2. & $\begin{array}{l}\text { Keterampilan } \\
\text { Merumuskan Hipotesis }\end{array}$ & $42,4 \%$ & $79,5 \%$ & $37,3 \%$ \\
\hline 3. & $\begin{array}{l}\text { Keterampilan } \\
\text { Merencanakan } \\
\text { Percobaan }\end{array}$ & $46,2 \%$ & $85,7 \%$ & $39,5 \%$ \\
\hline 4. & $\begin{array}{l}\text { Keterampilan melakukan } \\
\text { percobaan }\end{array}$ & $54,3 \%$ & $90,5 \%$ & $36,2 \%$ \\
\hline 5. & $\begin{array}{l}\text { Keterampilan } \\
\text { memprediksi }\end{array}$ & $43,3 \%$ & $80,9 \%$ & $37,6 \%$ \\
\hline 6. & $\begin{array}{l}\text { Keterampilan } \\
\text { Menerapkan konsep }\end{array}$ & $41,9 \%$ & $78,6 \%$ & $36,7 \%$ \\
\hline
\end{tabular}




\begin{tabular}{|l|l|c|c|c|}
\hline 7. & $\begin{array}{l}\text { Keterampilan } \\
\text { berkomunikasi }\end{array}$ & $41,9 \%$ & $80 \%$ & $38,1 \%$ \\
\hline
\end{tabular}

Hasil penelitian yang diperoleh setelah menggunakan media pembelajaran tidak serta merta dapat memperoleh persentase yang tinggi secara keseluruhan. Ada beberapa indikator yang memang harus membutuhkan proses yang tidak sebentar dalam merubah setiap indikator. Mahasiswa mengamalami proses perubahan dalam proses pembelajaran yang berbeda pada setiap mata kuliah yang berbeda.

\section{PENUTUP}

\section{Kesimpulan}

Dari hasil penelitian dapat dilihat persentase setiap indikatornya mengamalami peningkatan penilaian secara klasikal terhadap keterampilan proses IPA yang dimiliki mahasiswa dengan menerapkan media pembelajaran Pop Up book. Pada indikator 1 keterampilan mengamati sebelum menggunakan media yaitu 49,1\% dan sesudah menggunakan media yaitu 82,9\%, indikator 2 keterampilan merumuskan hipotesis sebekum menggunakan media yaitu $42,4 \%$ dan sesudah menggunakan media 79,5\%, indikator 3 keterampilan merencanakan percobaan sebekum menggunakan media yaitu 46,2\% dan sesudah menggunakan media 85,7\%, indikator 4 keterampilan melakukan percobaan sebekum menggunakan media yaitu 54,3\% dan sesudah menggunakan media 90,5\%, indikator 5 keterampilan memprediksi sebekum menggunakan media yaitu 43,3\% dan sesudah menggunakan media 80,9\%, indikator 6 keterampilan menerapkan konsep sebekum menggunakan media yaitu 41,9\% dan sesudah menggunakan 
media $78,6 \%$, indikator 7 keterampilan berkomunikasi sebekum menggunakan media yaitu 41,9\% dan sesudah menggunakan media 90\%, Dari hasil yang diperoleh dapat terlihat penggunaan media pembelajaran Pop Up Book dapat meningkatkan keterampilan proses IPApada mahasiswa PGSD.

\section{Saran}

Setelah penelitian ini selesai diharapkan mahasiswa agar selalu mengulangi kembali dan fokus secara baik pada mata kuliah yang diajarkan khususnya mata kuliah IPA yang setiap semester ada dalam mata kuliah mahasiswa PGSD. Hal ini diharapkan agar mahasiswa memiliki keterampilan proses IPA sebagai modal mempersiapkan diri sebagai calon guru yang memiliki kreatifitas dan karya sederhana namun dapat meningkatkan motivasi belajar siswa nantinya dengan menggunakan model pembelajaran yang dibuat.

\section{DAFTAR PUSTAKA}

Aristo, R. 2008. Media Pembelajaran. Jakarta : Departemen Pendidikan Nasional

Arsyad. A. 2010. Media Pembelajaran (Edisi Revisi). Raja Grafindo Persada. Jakarta

Hughes, R.L. Jones,S.K. 2011. Developing and Assessing College Student Teamwork Skills. Wiley Periodicals, Inc.Published online in Wiley Online Library (wileyonlinelibrary.com)

Purwanto. 2011. Evaluasi Hasil Belajar. Pustaka Belajar. Yogyakarta.

Sanaky. H. AH. 2013. Media Pembelajaran Interaktif - Inovatif. Kaukaba Dipantara : Yogyakarta.

Sadiman. A.S. 2014. Media Pendidikan : Pengertian, Pengembangan dan Pemanfaatannya. Raja Grafindo Pustaka. Jakarta. 
Sani, R.A. 2014. Inovasi Pembelajaran.Bumi Aksara. Jakarta.

Sanjaya, W. 2012. Strategi Pembelajaran Berorientasi Standar Proses Pendidikan. Kencana. Jakarta. 